\title{
PLANO DE AÇÕES ARTICULADAS NA GESTÃO DA EDUCAÇÃO DE MUNICÍPIOS PERTENCENTES À ASSOCIAÇÃO DOS MUNICÍPIOS DA ZONA DA PRODUÇÃO (AMZOP)-RS
}

\author{
PLAN DE ACCIONES ARTICULADO EN LA GESTIÓN DE LA EDUCACIÓN \\ DE MUNICIPIOS PERTENECES A LA ASOCIACIÓN DE MUNICIPIOS DEL ÁREA \\ DE PRODUCCIÓN (AMZOP)-RS
}

\author{
ARTICULATED PLAN OF ACTIONS IN THE MUNICIPALITIES' EDUCATION \\ MANAGEMENT BELONGING TO THE ASSOCIATION OF MUNICIPALITIES IN \\ THE PRODUCTION AREA (AMZOP)-RS
}

\author{
Silvana Maria Tres CICHELERO ${ }^{1}$ \\ Elisiane Machado LUNARDI ${ }^{2}$ \\ Carla da Luz ZINN ${ }^{3}$
}

RESUMO: Este estudo tem como objetivo analisar os limites e as possibilidades que o Plano de Ações Articuladas - PAR traz para a gestão da Educação de municípios do estado do Rio Grande do Sul pertencentes à AMZOP (Associação dos Municípios da Zona da Produção). De abordagem qualitativa (FLICK, 2009; 2012), como estudo de casos múltiplos (YIN, 2001; TRIVIÑOS, 1987), foram utilizados questionários Google para a coleta de dados, enviados via link de acesso a todas as Secretarias de Educação dos municípios da AMZOP/RS. Para fins de análise, foi usada a triangulação de dados (GIL, 2008; FLICK, 2009) e a análise de conteúdo (BARDIN, 2011). A partir disso, elencou-se os limites e as possibilidades que o PAR trouxe à educação nos municípios participantes da pesquisa. A principal possibilidade foi o acesso a recursos financeiros de infraestrutura para as redes de ensino e a principal limitação foi a centralização dos recursos e das decisões na esfera federal. O estudo confirma mudanças singulares na gestão da educação nos municípios pertencentes à $\mathrm{AMZOP} / \mathrm{RS}$, a partir do PAR. É preciso uma análise crítica do plano e da gestão que vem sendo desenvolvida, referente à democratização da educação a partir dos princípios da autonomia, descentralização de poder e da participação efetiva da comunidade.

PALAVRAS-CHAVE: Políticas públicas educacionais. Plano de Ações Articuladas. Gestão da educação municipal. Gestão democrática.

1 Centro de Ensino Superior Riograndense (CESURG), Sarandi - RS - Brasil. Professora no Curso de Pedagogia. Pesquisadora do Grupo REDES de Estudos e Pesquisas em Políticas Públicas e Gestão Educacional. Mestre em Políticas Públicas e Gestão Educacional (UFSM). ORCID: https://orcid.org/0000-0001-6878-3812. E-mail: syl.tres@gmail.com

2 Universidade Federal de Santa Maria (UFSM), Santa Maria - RS - Brasil. Professora Adjunta no Departamento de Administração Escolar. Doutorado em Educação (PUCRS). ORCID: https://orcid.org/00000002-2276-2466. E-mail: elisiane.lunardi@gmail.com

${ }^{3}$ Universidade Federal de Santa Maria (UFSM), Santa Maria - RS - Brasil. Mestrado pelo Programa de PósGraduação em Políticas Públicas e Gestão Educacional. Pesquisadora do Grupo REDES de Estudos e Pesquisas em Políticas Públicas e Gestão Educacional. ORCID: https://orcid.org/0000-0002-5668-5315. E-mail: carlazinn@gmail.com

RIAEE - Revista Ibero-Americana de Estudos em Educação, Araraquara, v. 16, n. esp. 2, p. 1093-1112, maio 2021. e-ISSN: 1982-5587 
RESUMEN: Este estudio tiene como objetivo analizar los límites y posibilidades que el Plan de Acción Conjunto - PAR aporta a la gestión de la Educación en los municipios del Estado de Rio Grande do Sul pertenecientes a AMZOP (Asociación de Municipios de la Zona de Producción). Con un enfoque cualitativo (FLICK, 2009; 2012), como un estudio de caso múltiple (YIN, 2001; TRIVIÑOS, 1987). Para la recogida de datos se utilizaron cuestionarios de Google, enviados a través de un enlace de acceso a todos los Departamentos de Educación de los municipios de AMZOP / RS. Para fines de análisis se utilizó la triangulación de datos (GIL, 2008; FLICK, 2009) y el análisis de contenido (BARDIN, 2011). A partir de esto, se enumeraron los límites y posibilidades que el PAR trajo a la educación en los municipios participantes en la investigación. La principal posibilidad era el acceso a recursos de infraestructura financiera para las redes educativas y la principal limitación era la centralización de recursos y decisiones a nivel federal. El estudio confirma cambios singulares en la gestión de la educación en los municipios pertenecientes a AMZOP / RS, del $P A R$. Es necesario un análisis crítico del plan y la gestión que se está desarrollando, en cuanto a la democratización de la educación en base a los principios de autonomía, descentralización del poder y participación comunitaria efectiva.

PALABRAS CLAVE: Políticas públicas educativas. Plan de Acción Articulado. Gestión educativa municipal. Gestión democrática.

ABSTRACT: This study aims to analyze the limits and possibilities that the Joint Action Plan - PAR brings to the education management in municipalities in the State of Rio Grande do Sul belonging to AMZOP (Association of Municipalities in the Production Zone). We adopted a qualitative approach (FLICK, 2009; 2012), which characterizes our study as a multiple case study (YIN, 2001; TRIVIÑOS, 1987). We use Google questionnaires for data collection, through which we send an access link to all Education Departments in the municipalities of AMZOP / RS. For analysis purposes, we use data triangulation (GIL, 2008; FLICK, 2009) and content analysis (BARDIN, 2011). We listed the limits and possibilities that PAR brought to education in the municipalities participating in the research. The main result we found was access to financial infrastructure resources for education networks. The main limitation we can highlight was the centralization of resources and decisions at the federal level. The study confirms singular changes in education management in the municipalities belonging to AMZOP / RS, from PAR. There is a need for a critical analysis of the plan and management that is municipalities are developing. It regards democratization based on the principles of autonomy, power decentralization, and effective community participation.

KEYWORDS: Educational public policies. Articulated Action Plan. Municipal education management. Democratic management.

\section{Introdução}

Este estudo é fruto das discussões e das pesquisas realizadas no âmbito do Grupo REDES de Estudos e Pesquisas em Políticas Públicas e Gestão Educacional/CNPq, vinculado à Universidade Federal de Santa Maria (UFSM), que teve como tema o Plano de Ações Articuladas (PAR) e suas implicações na gestão da educação dos municípios pertencentes à

RIAEE - Revista Ibero-Americana de Estudos em Educação, Araraquara, v. 16, n. esp. 2, p. 1093-1112, maio 2021. e-ISSN: 1982-5587 
Associação dos Municípios da Zona da Produção $\left(\mathrm{AMZOP}^{4}\right)$, região norte do Estado do Rio Grande do Sul, buscando uma análise à luz dos princípios da gestão democrática da educação, durante o ano de 2018 (dois mil e dezoito).

Assim, o Plano de Ações Articuladas, como parte do Plano de Metas Compromisso Todos Pela Educação, surgiu trazendo inúmeras dúvidas e incertezas. No decorrer deste tempo de implantação e implementação do PAR, inúmeros questionamentos foram surgindo, entre eles: a legislação determina a gestão democrática da educação, no entanto, o governo federal tomou para si a criação de Políticas Públicas, as quais os municípios aderiram via PAR, com o objetivo principal de obter recursos financeiros; o PAR é dividido em quatro dimensões: 1 - Gestão Educacional; dimensão 2 - Formação de Professores e de Profissionais de Serviço e Apoio Escolar; dimensão 3 - Práticas Pedagógicas e Avaliação e dimensão 4 Infraestrutura Física e Recursos Pedagógicos. No entanto, acabou que a atenção se voltou quase que exclusivamente para a quarta, o que possibilitaria o recebimento de recursos financeiros. Nesse sentido, o PAR surgiu como um instrumento metodológico de cooperação entre Município e União, para o planejamento e gestão da educação de forma democrática e participativa. Mas será que foi isso mesmo o que aconteceu?

Então, esses questionamentos deram origem à problemática de pesquisa: quais os limites e as possibilidades trazidos pelo Plano de Ações Articuladas à Gestão da Educação dos municípios pertencentes à região da AMZOP (Associação dos Municípios da Zona da Produção)? Indagações estas que objetivaram analisar os limites e as possibilidades trazidos pelo Plano de Ações Articuladas - PAR para a gestão da Educação de municípios do estado do Rio Grande do Sul pertencentes à AMZOP (Associação dos Municípios da Zona da Produção).

Por esta razão, visando compreender melhor a proposta de gestão trazida pelo PAR às redes municipais de ensino e como se deu sua implementação, foi desenvolvida uma pesquisa de natureza qualitativa, tendo como locus de investigação os municípios do Norte do Rio Grande do Sul, pertencentes à Associação dos Municípios da Zona da Produção (AMZOP). Logo, foi desenvolvida uma pesquisa social de natureza qualitativa, do tipo estudo de casos múltiplos (TRIVIÑOS, 1987), que considerou a lógica da "replicação" (YIN, 2001),

${ }^{4}$ A FAMURS (Federação das Associações de Municípios do Rio Grande do Sul) é a entidade representante dos 497 (quatrocentos e noventa e sete) municípios gaúchos, reunindo prefeitos, vice-prefeitos, secretários, técnicos e órgãos da gestão pública municipal. Ela divide o estado em 27 (vinte sete) Associações Regionais. A AMZOP é uma delas, sendo a maior representação regional do municipalismo gaúcho, agregando 43 (quarenta e três) municípios localizados na região norte do estado. Tem como finalidade "proporcionar a integração política de seus membros, prestando assistência técnica, respeitada a autonomia de cada municipalidade" (AMZOP, 2013, Art. $\left.4^{\circ}\right)$. 
ou seja, a resposta, a argumentação, e não somente a amostragem, utilizando, dessa maneira, como instrumento de construção de dados, o questionário on-line, organizado através da ferramenta Google Forms.

Assim, para a efetivação da pesquisa, o link da página do questionário foi enviado a todas as 43 (quarenta e três) Secretarias de Educação dos municípios da AMZOP, obtendo resposta de 22 (vinte e dois) questionários, o que equivale a 51\% (cinquenta e um por cento) do total. O preenchimento dos questionários foi realizado pelos Dirigentes/Secretários Municipais de Educação (45,5\%), pelos Técnicos da Secretaria Municipal da Educação Responsável pelo PAR (45,5\%), pela Diretora dos Programas da Secretaria Municipal de Educação (4,5\%) e pela Coordenadora Pedagógica da SME (4,5\%). Destes, 21 (vinte e um) participaram da elaboração do PAR 2016/2019, sendo que nove participaram também da elaboração de um dos planos anteriores, conforme mostra a figura a seguir:

Figura 1 - Gráfico da Função do responsável pelo preenchimento do questionário aplicado na pesquisa

- Dirigente/ Secretário(a) Municipal da Educação

- Técnico da Secretaria Municipal da Educação Responsável pelo PAR

- Diretora dos Programas da SMECD

Coordenadora Pedagógica

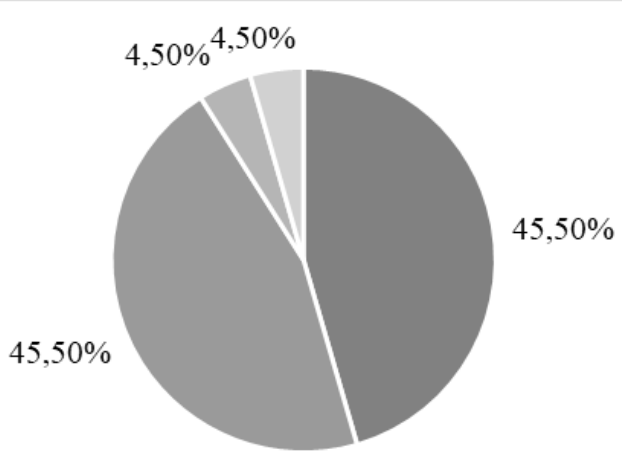

Fonte: Elaborado pelas autoras

Figura 2 - Gráfico da Participação dos responsáveis pelo preenchimento do questionário na elaboração do PAR (2008-2019)

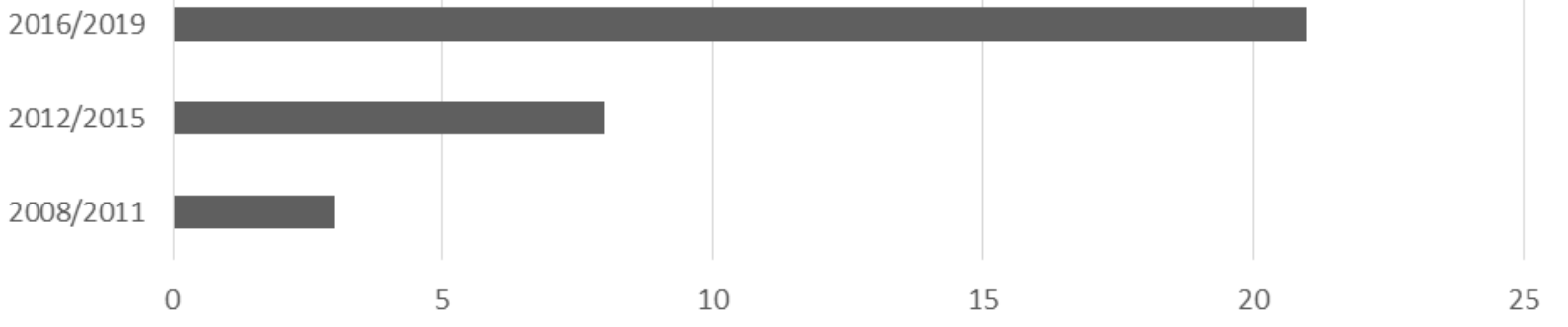

Fonte: Elaborado pelas autoras 
Os dados coletados permitiram analisar a organização da gestão da educação nos municípios a partir das premissas da Gestão Democrática: autonomia, descentralização de poder e participação. Bem como apontar as principais implicações do Plano de Ações Articuladas na gestão da educação nesses municípios. O tratamento dos resultados se deu por meio da análise de conteúdo, considerando as categorias de análise e suas subcategorias, sendo estas últimas oriundas dos dados produzidos: Gestão da Educação Municipal (Diálogo e representatividade, Planejamento, Financiamento, Formação Continuada, Lei de Gestão Democrática do Ensino e Cooperação Técnica); Gestão Democrática (Autonomia, Descentralização de Poder, Participação e Órgãos Colegiados) e Plano de Ações Articuladas (Dimensão 1 - Gestão Educacional; Dimensão 2 - Formação de Professores e de Profissionais de Serviço e Apoio Escolar; Dimensão 3 - Prática Pedagógicas e Avaliação e Dimensão 4 Infraestrutura Física e Recursos Pedagógicos, Regime de Colaboração, Limites e Possibilidades). Destaca-se que a categoria 'Gestão Democrática' foi analisada transversalmente, assumindo o papel de interlocutora entre as outras categorias e suas subcategorias. A partir disso foram organizadas as duas sessões que compõem o corpo do estudo.

\section{A gestão da educação municipal na região da AMZOP: uma análise à luz dos princípios da gestão democrática}

Nesta seção, estão elencados os dados referentes à gestão da educação nos municípios da AMZOP, correlacionando-os às categorias de análise: Gestão Municipal e Gestão Democrática, à luz dos princípios da autonomia, descentralização de poder e participação.

A Gestão Democrática é o princípio legal da Educação, instituído pela Constituição Federal (BRASIL, 1988, art. 206), pela Lei de Diretrizes e Bases da Educação Nacional (BRASIL, 1996, art. 3º, VIII) e pelo Plano Nacional de Educação (BRASIL, 2014, Art.2º, VI). A LDBEN reitera ainda que os sistemas municipais de ensino definirão as normas de gestão democrática, de acordo com suas peculiaridades, considerando a participação dos profissionais da educação na elaboração dos projetos político pedagógicos das escolas e das comunidades escolares em órgãos colegiados (BRASIL, 1996, art. 14, I-II). Por sua vez, o Plano Nacional da Educação (BRASIL, 2014) dedica à Gestão Educacional Democrática a Meta 19: 
desempenho e à consulta pública à comunidade escolar, no âmbito das escolas públicas, prevendo recursos e apoio técnico da União para tanto.

Esta meta conta com oito estratégias para sua concretização, das quais destacam-se, no tocante aos sistemas municipais de ensino, a 19.5, que trata da constituição e do fortalecimento dos Conselhos Municipais de Educação e dos Conselhos Escolares, como instrumentos (mecanismos) de participação e fiscalização da gestão educacional e escolar; a estratégia 19.6, que estimula a participação de todos os membros da comunidade escolar na construção e avaliação dos Projetos Político-Pedagógicos, dos currículos, dos regimentos e dos planos de gestão escolar; e a estratégia 19.7, que visa fortalecer os processos de autonomia pedagógica, administrativa e de gestão financeira dos estabelecimentos de ensino.

Depois, buscando compreender a organização da gestão democrática dos municípios participantes da pesquisa, realizou-se uma análise das Leis de Gestão Democrática dos 11(onze) municípios, que na ocasião já contavam com sua aprovação, buscando averiguar como está legalmente organizada a Gestão da Educação Municipal, a partir dos princípios da autonomia, descentralização e participação. Cabe ressaltar aqui que das 11 (onze) leis analisadas, nove se limitam a normatizar a gestão escolar, ou seja, a nível de estabelecimento de ensino, e somente duas referiam-se à gestão educacional, ou seja, a nível de sistema de ensino.

Os municípios que abarcam em sua legislação a gestão educacional apresentavam como mecanismos de participação as instâncias colegiadas: Conferência Municipal de Educação, o Fórum Municipal de Educação, o Conselho Municipal de Educação, o Conselho de Acompanhamento e Controle Social do FUNDEB e o Conselho de Alimentação Escolar. Todos os municípios determinam que os Conselhos Escolares, Círculos de Pais e Mestres, e em alguns casos, o Grêmio Estudantil, são os mecanismos de participação na gestão escolar.

Verificou-se então que a participação ficou atrelada aos Órgãos Colegiados, principalmente ao Conselho Escolar, que foi definido como corresponsável pela administração dos estabelecimentos de ensino. A autonomia apareceu em todas as leis como princípio básico da Gestão Democrática, contudo, em seis normativas, constava como "autonomia relativa (grifo nosso) dos estabelecimentos de ensino na gestão administrativa, financeira e pedagógica". Desta forma, os atos legais definiram como autonomia na gestão financeira dos estabelecimentos de ensino: a adesão aos Programas do MEC/FNDE; a participação na elaboração do orçamento anual e a aplicação e prestação de contas dos recursos financeiros decorrentes dos Programas Federais e/ou de outras instituições e iniciativas. Como autonomia na gestão administrativa, definiram: a escolha dos 
representantes dos órgãos colegiados pela comunidade escolar, a participação da comunidade nos conselhos escolares e a participação dos conselhos na elaboração dos Projetos Político Pedagógicos. Por último, como autonomia na gestão pedagógica, foram elencados o aperfeiçoamento dos profissionais da educação e a participação na elaboração do Projeto Político Pedagógico.

Conforme os dados referentes à efetividade deste princípio na gestão educacional dos municípios, e com base na análise dos mecanismos legais, pode-se dizer que o princípio da autonomia estava contemplado na gestão municipal dos municípios, contudo, poderia ser aprimorado e melhor efetivado, sendo necessário para isso o aprofundamento da concepção de autonomia na gestão, e tudo que este princípio engloba, para poder ampliá-lo e aprimorá-lo em cada contexto e em cada órgão dos sistemas municipais de ensino. Pois, conforme Luck (2013, p. 104):

Essa autonomia se constrói com autoridade, isto é, com sentido de autoria. Trata-se de uma autoridade intelectual (capacidade conceitual), política (capacidade de compartilhar poder), social (capacidade de liderar e orientarse por liderança) e técnica (capacidade de produzir resultados e monitorálos).

Neste sentido, faz-se necessário a formação de 'autores' capacitados, intelectual, política, social e tecnicamente, para agirem coletivamente, com comprometimento, competência, liderança, mobilização, transparência, visão estratégica, proativa e criatividade na gestão, visando a melhoria da qualidade da educação e da vida em sociedade.

No que se refere à descentralização de poder, conforme os dados produzidos, o princípio recebeu uma avaliação mediana quanto à sua efetivação na gestão dos municípios. Assim, se for considerado que o processo de descentralização perpassa pela efetivação da autonomia administrativa, financeira e pedagógica, pela organização e atuação dos órgãos colegiados, e pela elaboração e efetivação do projeto político pedagógico, como forma de modificar as relações entre os sistemas centrais e as escolas, redistribuindo o poder decisório, pode-se dizer que este princípio estava contido na legislação municipal analisada, contudo, não era plenamente efetivado na organização da educação dos municípios.

Isso foi reiterado pelos dados sobre a gestão financeira dos recursos da educação, que demonstraram que a mesma ficava centralizada na Prefeitura Municipal, pelo fato que detinha a contabilidade, o planejamento e o gerenciamento da aplicação dos recursos da educação em $81,8 \%$ dos municípios, e pela razão da nomeação dos dirigentes escolares ser por indicação 
dos prefeitos. Em apenas dois municípios este poder era delegado para a comunidade escolar, através de escolha direta.

Nessa direção, nos cabe questionar se o que acontecia nas redes municipais de ensino poderia ser considerada descentralização do poder ou apenas uma redistribuição de tarefas e responsabilidades. Convém ressaltar que, para que este princípio seja efetivo, é preciso prover espaços de exercício de relações democráticas, possibilitando que as decisões políticas se concentram "[...] naqueles que se situam na base do sistema educacional (professores, técnicos, pais, comunidades" (CASTRO; LAUANDE, 2009, p. 9), o que por sua vez, não se concretizava.

Por último, analisou-se o princípio democrático da participação, o que foi avaliado positivamente, demonstrando sua efetividade na gestão educacional dos municípios investigados. Conforme a legislação municipal, a participação estava resguardada à comunidade escolar no que tangia à definição e à implementação de decisões pedagógicas, administrativas e financeiras, através dos órgãos colegiados. Como foi visto, os municípios possuíam os órgãos colegiados (Conselho Municipal de Educação, CACS-FUNDEB e Conselhos Escolares) instituídos e ativos. Contudo, sua participação envolvia esforços individuais em prol da coletividade, onde através da cooperação e do espírito de equipe se buscava efetivar os objetivos sociais e institucionais, assumindo a autoria e a responsabilidade pelas ações educacionais. Desta forma, não basta a existência legal dos órgãos colegiados, é necessário que os mesmos desempenhem seu papel gestor, assumindo, em conjunto com as Secretarias de Educação e Direção das Escolas, seu papel nas tomadas de decisões. Assim sendo, o princípio da participação requer melhorias e aprimoramento para que, unido aos princípios da autonomia e da descentralização pudesse, ser definida, como efetivamente democrática, a gestão da educação dos municípios em estudo.

\section{O Plano de Ações Articuladas e suas implicações na gestão da educação dos municípios da AMZOP}

O Plano de Ações Articuladas foi criado em 2007, como mecanismo de concretização do Plano de Metas Todos pela Educação (BRASIL, 2007a), com a função de auxiliar as secretarias de educação no planejamento de ações a partir do diagnóstico dos problemas educacionais enfrentados, objetivando solucioná-los através do regime de colaboração entre os entes federados. 
Como forma de garantir a participação democrática da comunidade local na construção deste plano, desde a identificação dos problemas educacionais enfrentados nos municípios, até a proposição de ações para solucioná-los, se fazia necessária a formação de uma Equipe Local, que tinha como função participar da elaboração, execução e monitoramento do PAR.

Dos 22 (vinte e dois) municípios participantes da pesquisa, três não organizaram a equipe local para a elaboração do PAR, o que fere o princípio democrático e participativo proposto pelo plano, afinal, acabaram por centralizar o poder decisório nas secretarias de educação, não considerando a opinião e os anseios da comunidade. Positivamente, 19 (dezenove) municípios formaram suas equipes locais, porém, como evidenciaram os dados quanto à sua atuação, ilustrada no gráfico a seguir, esta teve um caráter mediano, o que deixa espaço para questionar a efetivação do princípio democrático, desde a sua elaboração.

Figura 3 - Gráfico da Avaliação dos participantes da pesquisa quanto à atuação da Equipe Local na elaboração, execução, monitoramento e avaliação do Plano de Ações Articuladas (atribuição de notas de 1 a 5)

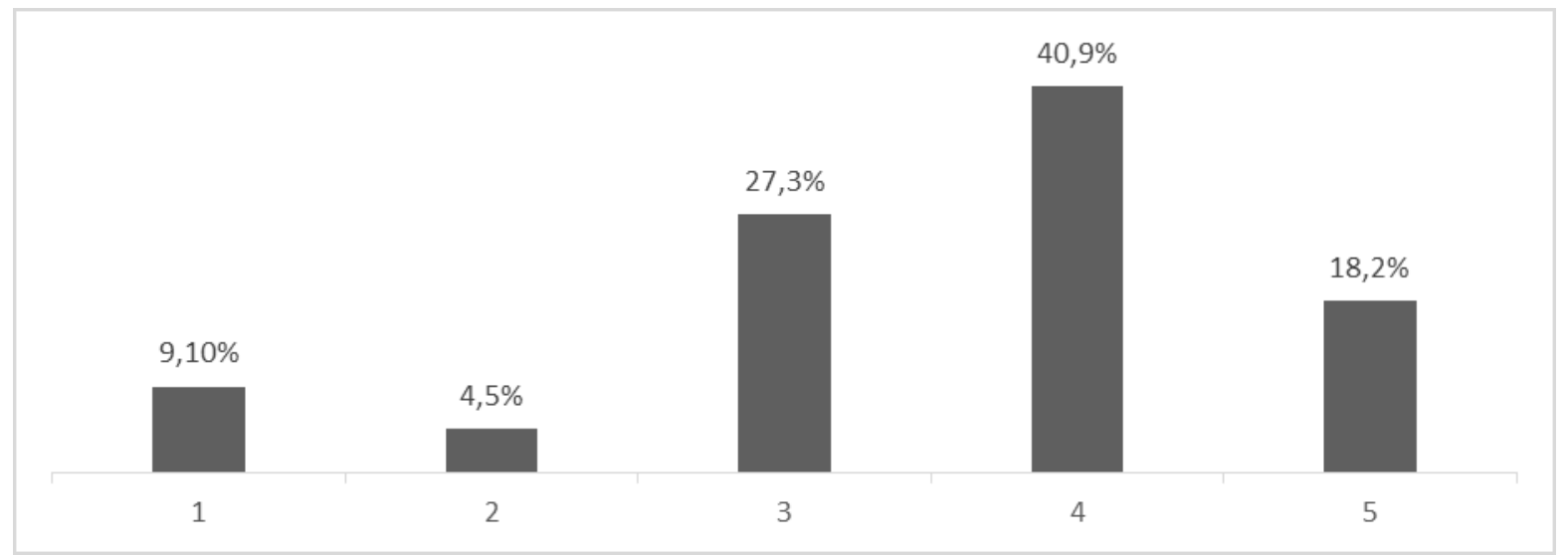

Fonte: Elaborado pelas autoras

\section{A implementação do PAR sob a ótica das Dimensões}

O Plano de Ações Articuladas contempla quatro dimensões: 1- Gestão Educacional; 2Formação de Professores e Profissionais em Serviço; 3- Práticas Pedagógicas e Avaliação e 4Infraestrutura Física e Recursos Pedagógicos. Neste contexto, intencionou-se avaliar como este plano foi assimilado e implementado nos municípios pertencentes à AMZOP, a partir de suas dimensões.

Conforme os dados coletados, 95,5\% (noventa e cinco por cento) dos municípios participantes do estudo passaram a ter mais recursos com o PAR, sendo que os mesmos 
incidiram, principalmente, na Dimensão 4 - Infraestrutura Física e Recursos Pedagógicos, mas não somente, constando referência a outras dimensões, à Educação como um todo, à melhoria da qualidade da educação e ao cumprimento de meta do Plano Nacional da Educação.

Analisando as respostas a respeito das implicações do PAR nas redes municipais de ensino, constatou-se que na Região da AMZOP se sobressai a da Dimensão 4, referente aos recursos financeiros. Contudo, outras dimensões e outras consequências são levantadas, mas com menor incidência. Isto não significa, a priori, que as demais dimensões não foram alcançadas. No entanto, as respostas coletadas permitiram supor que, em função das dificuldades financeiras que assolaram e assolam os municípios, em todas as áreas, a possibilidade de melhorar a infraestrutura das redes de ensino, com construções e ampliações de escolas, quadras esportivas, mobiliário, ônibus novos, entre outros, são ações que não conseguiriam ser implementadas com recursos próprios dos municípios, que acabam por fazer com que a Dimensão 4 se notabilize, a despeito das demais.

Outra resposta que cabe ressaltar é a que se refere ao cumprimento da Meta 1 do Plano Nacional de Educação, pois isto demonstra que estava havendo consonância do PAR com o PNE, novidade trazida pelo ciclo em vigência na época.

Meta 1: universalizar, até 2016, a educação infantil na pré-escola para as crianças de 4 (quatro) a 5 (cinco) anos de idade e ampliar a oferta de educação infantil em creches de forma a atender, no mínimo, $50 \%$ (cinquenta por cento) das crianças de até 3 (três) anos até o final da vigência deste PNE (BRASIL, 2014).

Quanto às ações, programas e projetos que os municípios passaram a desenvolver a partir da implantação do PAR, 13 (treze) fizeram referência à Dimensão 4, dez à Dimensão 3, oito à Dimensão 2 e um à Dimensão 1. Mais uma vez, a Dimensão que se sobressaiu foi a referente à Infraestrutura Física e Recursos Pedagógicos. Contudo, as Dimensões 2 e 3 também foram citadas. Cabe ressaltar que:

Desde o lançamento do Plano de Desenvolvimento da Educação (PDE), todas as transferências voluntárias e assistência técnica do MEC aos municípios, estados e Distrito Federal estão vinculadas à elaboração do Plano de Ações Articuladas (PAR). No plano, o gestor descreve o tipo de apoio que o estado ou município necessita, ao detalhar um conjunto de ações. Todos os que elaboraram o PAR podem receber assistência técnica e/ou financeira do MEC em diversas áreas (BRASIL, 2018).

Foi possível observar que entre as ações citadas pelos municípios, as mais lembradas quanto à infraestrutura foram as obras de ampliação, melhorias e construção de escolas e as 
melhorias no transporte escolar. Quanto às ações pedagógicas estavam os programas: Mais Educação, Mais Alfabetização, Saúde na Escola e a formação de professores, especialmente o PNAIC. Isso não significa que no decorrer destes dez anos de existência do PAR não foram desenvolvidos outros programas e projetos, contudo, esses ganharam mais evidência e significado, seja pelas necessidades de cada município, seja pela relevância que adquiriram para a educação local.

Quanto às implicações do PAR na Gestão Pedagógica das redes de ensino, destacaram-se: o aprimoramento da formação continuada; um maior alcance a programas e recursos, que facilitaram a garantia do direito ao acesso e permanência dos estudantes nas escolas, o que, por sua vez, está relacionado à gestão da educação como um todo, mas também com a gestão pedagógica, já que a garantia deste direito está diretamente ligada ao desenvolvimento do aprendizado e da qualidade educacional; às inovações e melhorias pedagógicas recorrentes do Plano, destacando a importância do espaço físico adequado e de qualidade para o desenvolvimento pedagógico e a importância do PAR como mecanismo de Planejamento da Educação para o quadriênio. Um dos objetivos pelos quais o PAR foi criado é, justamente, auxiliar as secretarias de educação a planejarem suas políticas educacionais e garantir que sejam mantidas mesmo com as trocas de governo (BRASIL, 2007b).

A respeito das modificações incrementadas no PAR 2016-2019, na opinião dos pesquisados, as mais relevantes referem-se às alterações a nível de Sistema (SIMEC) ${ }^{5}$, que o tornaram menos burocrático, mais prático e, claro, trazendo uma melhor organização e facilidade de acesso e planejamento das ações. Foi destacada também a possibilidade de adesão aos pregões eletrônicos automaticamente e a necessidade de as prestações de conta estarem em dia, para que se pudesse realizar novas solicitações. Cabe destacar que, conforme anunciado pelo MEC/FNDE, uma das principais modificações realizadas para este ciclo foi a articulação do PAR ao Plano Nacional de Educação (BRASIL, 2014), de modo que as ações propostas no primeiro viabilizassem atingir as metas do segundo. Contudo, isto não foi lembrado por nenhum dos pesquisados ao responder esta questão.

${ }^{5}$ O Sistema Integrado de Monitoramento, Execução e Controle do Ministério da Educação (Simec) é um portal operacional e de gestão do MEC, que trata do orçamento e monitoramento das propostas on-line do governo federal na área da educação. É no Simec que os gestores verificam o andamento dos Planos de Ações Articuladas em suas cidades. Disponível em: http://portal.mec.gov.br/secretaria-de-regulacao-e-supervisao-da-educacaosuperior-seres/114-conhecaomec-1447013193/sistemas-do-mec-88168494/143-simec. Acesso em: 10 jul. 2020. 


\section{O PAR e o Regime de Colaboração: descentralização ou centralização}

O Plano de Desenvolvimento de Educação (PDE), tinha como um de seus pilares o Regime de Colaboração entre os entes federados. O PAR, instrumento de concretização do PDE, foi idealizado como sendo um mecanismo democrático de planejamento e gestão da educação, com o intuito de efetivar o regime de colaboração. Assim sendo, buscou-se avaliar a efetividade de sua função descentralizadora e articuladora da gestão educacional nos municípios da AMZOP.

Neste contexto, foi solicitada a opinião dos pesquisados a respeito do PAR. A grande maioria relatou que o plano: auxiliou o município a cumprir suas metas educacionais $(86,4 \%)$; permitiu ampliar os recursos financeiros destinados à educação $(81,8 \%)$; promoveu a aproximação do município à União, permitindo maior articulação e melhorias na gestão educacional $(72,7 \%)$ e passando a ser um adendo às ações que já vinham sendo desenvolvidas $(63,6 \%)$, conforme ilustra a figura 4 .

Figura 4 - Gráfico da Opinião dos participantes da pesquisa em relação ao PAR:

As açōes do PAR passaram a ser um adendo às açð̃es que já vinham sendo desenvolvidas.

As ações do PAR passaram a ser prioridade para o municipio.

O PAR centralizou as decisões sobre programas e projetos para educação.

O PAR permitiu ampliar os recursos financeiros destinados à educação.

O PAR promoveu a aproximação do municipio e a união, permitindo maior articulação e melhorias na..

O municipio teve que mudar a política que vinha desenvolvendo para cumprir os compromissos..

O PAR veio auxiliar o município a cumprir suas metas educacionais.

\section{$63,64 \%$}

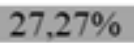

$31,82 \%$

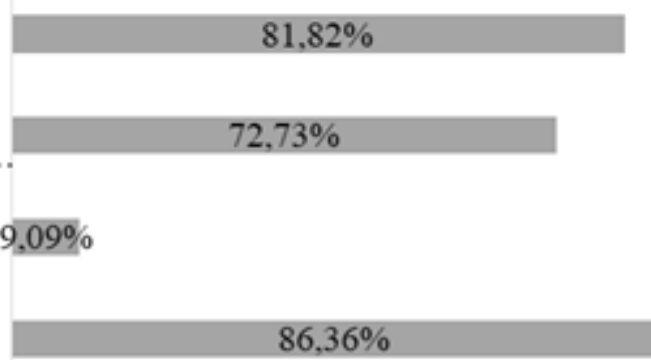

Fonte: Elaborado pelas autoras

Percebeu-se assim que o PAR foi avaliado positivamente, pois auxiliou-os no cumprimento de suas metas educacionais, bem como promoveu a aproximação e uma maior articulação entre Municípios e União. Ou seja, de certa forma, atendeu a um dos seus objetivos: a concretização do regime de colaboração, entendido como o compartilhamento de atribuições políticas, técnicas e financeiras para a manutenção e desenvolvimento da educação, respeitando a autonomia de cada ente federado (BRASIL, 2007b). Contudo, fica 
evidente que esta colaboração se deu, em alto grau, através da responsabilidade supletiva da União em financiar a educação.

Em menor intensidade, porém considerável a ponto de ser analisada, estão as questões do PAR centralizar as decisões sobre programas e projetos para a educação $(31,8 \%)$ e de suas ações passarem a ser prioridade para os municípios (27,3\%). Isto demonstra seu viés centralizador, mesmo que seja a opinião de uma proporção menor de municípios.

Por conseguinte, buscou-se saber como os municípios avaliam sua adesão e compromisso, assim como a adesão e o compromisso do MEC/FNDE, com as ações estabelecidas no PAR. Sendo que, consideraram que seu comprometimento com a implementação do plano foi significativamente maior do que o comprometimento do MEC/FNDE, que ficou aquém das expectativas dos municípios. Mesmo assim, consideraram que o plano aprimorou a relação entre os entes federados. Isto poderia ser atribuído ao fato de que, até então, as relações entre municípios e União necessitavam de intermediários (deputados, senadores, ...) e o PAR acabou por encurtar este caminho, influenciando positivamente na autonomia do município.

Desta forma, o PAR foi considerado por $86 \%$ dos pesquisados, importante para o aprimoramento da gestão da educação municipal, 63,6\% o avaliaram como democrático, $54,5 \%$ inovador e $50 \%$ participativo. Um número menor de pesquisados o apontou como burocrático (40,9\%) e gerencial (36,4\%), sendo que $18,2 \%$ o classificaram como descentralizador e o mesmo número como centralizador. Todavia, não foi apontado como desnecessário por nenhum dos pesquisados (Figura 5), ou seja, uma avaliação positiva do plano.

Figura 5 - Gráfico do PAR, como mecanismo de gestão e de planejamento é considerado

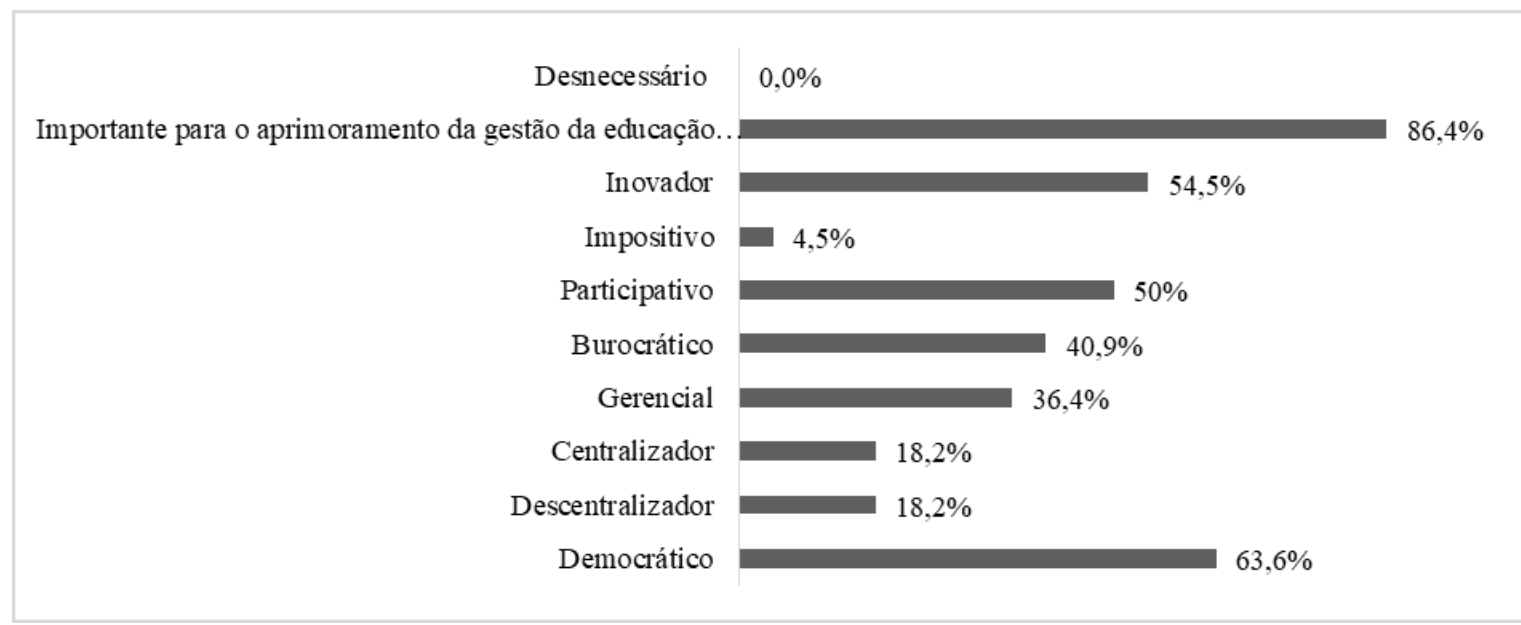

Fonte: Elaborado pelas autoras 
Por sua vez, quando questionado se a política educacional, com a implementação do PAR, foi redirecionada em função dos interesses federais, as opiniões se dividiram: cinco não foram específicos em suas respostas, ressaltando a ação conjunta dos municípios e a União em prol da educação, promovida pelo plano; sete consideram que a política educacional não foi redirecionada para atender os interesses federais; e os outros dez declaram que sim, o PAR ocasionou mudanças nas políticas educacionais dos municípios, para atender aos interesses da União. Assim, evidenciaram que o PAR promoveu a parceria entre os municípios e a União, remetendo ao conceito de regime de colaboração entre os entes federados, um dos pilares do Plano de Desenvolvimento da Educação. Contudo, não se pode reduzir o conceito de regime de colaboração à formação de parcerias, visto que, para que se concretize, é necessário que haja uma cooperação entre as esferas, de modo que compartilhem as competências políticas, técnicas e financeiras, sem ferir a autonomia, em prol da qualificação educacional.

Isto posto, outras respostas revelaram a importância que o PAR adquiriu na gestão da educação municipal, e ao mesmo tempo a dependência desta em relação ao plano. Isto ratifica a ideia trazida por Souza e Castro (2017), quando afirmam a ambivalência de seu discurso, ao propor o regime de colaboração, enquanto condiciona esta colaboração (assistência técnica/financeira) à mudança organizacional da gestão da educação municipal, de forma a adequá-la às quatro dimensões do plano.

Quanto às respostas afirmativas à questão em análise, grande parte fazia referência aos possíveis recursos oriundos do PAR. Mas quatro em especial corroboraram com a hipótese que impulsionou este estudo: o Plano de Ações Articuladas é um instrumento que centraliza as decisões na esfera federal, cabendo aos municípios executá-las. Esta ideia de centralização da tomada de decisões na esfera federal é reiterada por Souza e Castro (2017, p. 890), ao afirmarem que os subgovernos foram subestimados como formuladores de políticas públicas, cabendo a estes a implementação das políticas do governo central:

Há na divisão de poder e autoridade propostos pelo PAR a convivência de vários centros de poder representados pelos três entes, mas que possuem capacidades desiguais; fazendo os subgovernos tomarem o PAR enquanto espaço de negociação política (barganhas constantes para influenciar decisões que afetam seus interesses). Embora o governo federal tenha centralizado as ações e decisões do PAR em suas mãos, não significa que os outros entes foram eliminados do jogo federativo.

Neste contexto, pode-se afirmar que os municípios tiveram sua capacidade de decisão conjunta subjugada, sendo implementada através do PAR a ideia de "satisfação do cliente", como estratégia para tornar a gestão mais eficiente e eficaz na busca por resultados, o que já 
havia sido anunciado por Saviani em 2007. Para isso, efetiva-se a descentralização das ações, que passam a ser responsabilidade dos municípios, mas não dos recursos financeiros necessários, que continuam sendo geridos a nível nacional.

\section{Limites e possibilidades do PAR: considerações finais}

Este estudo foi motivado pela vivência prática no trabalho com o Plano de Ações Articuladas. As incertezas e as indagações por ele trazidas à gestão da educação deram origem ao tema: a Gestão da Educação Municipal, a partir da implementação do Plano de Ações Articuladas.

Assim, a pesquisa objetivou analisar os limites e as possibilidades trazidos pelo Plano de Ações Articuladas para a gestão dos municípios do estado do Rio Grande do Sul pertencentes à AMZOP (Associação dos Municípios da Zona da Produção), no que se refere a sua democratização.

Como principal possibilidade trazida pela sua implementação nos municípios, destacou-se o acesso a recursos financeiros de infraestrutura para os sistemas de ensino, tendo possibilitado também o desenvolvimento de programas ligados à formação dos professores e demais profissionais da educação, bem como voltados aos estudantes, além de incentivar a gestão democrática, através da criação e atuação de diversos conselhos.

Como principais limitações apareceram o enfoque muito atrelado à Dimensão 4, ligada ao repasse de recursos financeiros e à infraestrutura física, principalmente; a dificuldade em trabalhar e gerenciar a plataforma do PAR e, sobretudo, o desenvolvimento das ações em parceria com o FNDE/MEC, devido à centralização dos recursos e das decisões na esfera federal. Isso comprovou a hipótese do estudo, pois as decisões mais impactantes para a educação ficaram atreladas à esfera federal, reportando ao problema/tema da pesquisa, comprovando a centralização das decisões e o papel coadjuvante dos municípios na gestão de sua educação.

Contudo, são notáveis as implicações do PAR na gestão dos municípios da AMZOP. Certamente, ele modificou a forma de pensar e de organizar a gestão da educação municipal. Por mais que grande parte dos municípios sinalizaram que não modificaram a sua gestão para atender às demandas do plano, fica claro que isso aconteceu: quando afirmaram aderência aos programas de governo, caso contrário iriam perder seus recursos financeiros; quando relataram as inúmeras ações, projetos e programas que desenvolveram; quando organizaram os seus sistemas de ensino e os órgãos colegiados, entre outras demandas do PAR. 
Desta forma, o PAR influenciou determinantemente a gestão da educação municipal, trazendo inúmeras possibilidades de melhorias para a gestão, para a infraestrutura física e pedagógica, o que refletiu diretamente na qualidade do ensino ofertado. Ou seja, diversos foram os ganhos. Mesmo assim, não é possível afirmar que cumpriu com êxito seu objetivo de ser um plano que efetivasse a Gestão Democrática na sua plenitude. E isso é ratificado por diversos motivos: a forma como se deu sua implantação e implementação, implicitamente, impositiva, pois quem não aderisse ao $\mathrm{PDE} / \mathrm{Compromisso}$ Todos pela Educação e não elaborasse o Plano de Ações Articuladas não poderia pleitear por recursos financeiros e nem participar dos programas do FNDE, o que obrigou todos os municípios à adesão.

Em relação ao Layout do programa, o mesmo foi pensado e definido sem considerar a diversidade territorial e cultural brasileira. E o principal, configurou-se, sim, em um instrumento centralizador, pois reteve na esfera federal os recursos, a tomada de decisão sobre os projetos, os programas e ações, cabendo aos municípios a sua execução.

Em suma, por mais que as opiniões diretas dos municípios não retrataram a característica gerencial, centralizada, de participação e autonomia limitadas, uma análise mais profunda das questões abertas deixou transparecer que o PAR é um mecanismo limitado, gerencial, centralizador, que minimiza a autonomia dos municípios, envolto em véus de um discurso de gestão democrático-participativa, capaz de efetivar o regime de colaboração entre os entes federados, o que na prática não se efetivou.

Isso tudo acentuou a necessidade de uma análise mais aprofundada e crítica do PAR e da gestão que vem sendo desenvolvida, no que se refere à democratização da educação à luz dos princípios da autonomia, descentralização de poder e da participação efetiva da comunidade na tomada de decisões, uma vez que esses princípios não estavam plenamente incorporados e efetivos na gestão educacional e escolar dos Sistemas de Ensino da AMZOP.

Para que se possa democratizar a educação e utilizar o PAR como mecanismo de planejamento democrático e participativo seria preciso ressignificá-lo, e isso demandaria um estudo aprofundado que permitisse conhecer as bases teóricas e legais da gestão da educação, da gestão democrática e do plano, para que, em consonância com o conhecimento empírico dos gestores municipais, se construísse meios de utilizar o PAR como mecanismo de planejamento democrático e participativo da educação municipal.

Assim sendo, poder-se-ia propor uma mudança de foco, que consistiria em os municípios explorarem melhor as potencialidades de todas as quatro dimensões, buscando aprimorar as ações relacionadas à Gestão Educacional, principalmente no que se refere à 
democratização, possibilitando uma maior participação dos órgãos colegiados, promovendo a autonomia e a descentralização do poder.

Contudo, a sociedade brasileira encontra-se em um período de dúvidas frente ao caminho traçado por suas escolhas. A sua ainda frágil democracia está em perigo. É de conhecimento público que o Brasil passa por um período crítico. Envolto em uma crise política, econômica e, porque não dizer, dos valores democráticos. Muitas das conquistas sociais estão sendo questionadas, ignoradas e até desfeitas. Conforme Boaventura de Sousa Santos (apud ALMEIDA, 2018), chegou-se a um ponto de rotura com a democracia, alertando para o fato de que as ditaduras estão assumindo novas faces. Cita como exemplo o que vem acontecendo: “[...] no Brasil através de uma instrumentalização grotesca do poder judiciário para caricaturar a democracia sem a eliminar", acarretando o enfraquecimento das forças que lutam por ela.

Isso é assinalado por Santos (2016) como fascismo social, que se configura nas relações sociais quando a parte mais forte detém um poder muito maior que a parte mais fraca, a ponto de poder vetar seus desejos, necessidades e aspirações de vida digna.

Vivemos em sociedades politicamente democráticas e socialmente fascistas. Quanto mais se restringirem os direitos sociais e econômicos e quanto menos eficaz for a ação judicial contra as violações dos direitos existentes, maior será o campo do fascismo social (SANTOS, 2016).

Neste sentido, esta leitura da sociedade retrata muito da realidade vivida no Brasil. Vivencia-se o enfraquecimento das forças e lutas sociais, ao mesmo tempo em que se evidencia o autoritarismo, o extremismo, a rivalidade, e a perda de direitos sociais e econômicos, envoltos num discurso de 'nova política', de 'arrumar a casa', de 'salvadores da Pátria', "criminalizando o protesto social em nome da defesa da democracia" (SANTOS, 2016).

$\mathrm{Na}$ área da educação não é diferente. O Brasil encontrava-se num momento de construção de uma educação para todos, na busca pela equidade e pela qualidade. Muito se avançou neste sentido na última década. Contudo, hoje a educação brasileira caminha na esteira de incertezas, em um contexto de polaridade e embates de ordem política e partidária.

Por isso, é preciso tencionar o "por vir". É preciso pensar e analisar o Plano de Ações Articuladas a partir da conjuntura político-econômico-social atual do país. Neste cenário, torna-se desafiador prever o futuro das políticas públicas voltadas à educação, das quais faz parte o PAR. Ao mesmo tempo, compreender e reiterar a necessidade de efetivação da Gestão 
Democrática da Educação torna-se crucial, assim, no sentido de garantir a legitimação dos princípios democráticos.

Nesse viés, este estudo aponta que é imprescindível que se mantenha viva a chama da gestão democrática. Quanto aos educadores e às educadoras, os mesmos devem manter-se firmes em sua luta pela democratização da educação, para que se chegue à redemocratização da sociedade. Portanto, o conhecimento técnico, teórico e legal deve ancorar o planejamento na gestão educacional. Infere-se que o PAR é um mecanismo de gestão democrática que precisa ser planejado à luz da participação, da coletividade, da transparência e descentralização do poder.

Assim, ao analisar os limites e as possibilidades trazidas pelo plano para os municípios da AMZOP, é possível vislumbrar novas possibilidades e mudanças. Para isso, propõe-se retomar os estudos, compartilhar experiências, abastecer-se de novos saberes, e aprimorar a prática gestora, fortalecendo-se mutuamente. Enfim, é preciso ser resistência na luta pela educação como direito de todos, cumprindo e fazendo cumprir o dever do Estado, da família, e da sociedade na sua promoção, visando ao pleno desenvolvimento da pessoa, seu preparo para o exercício da cidadania (e da democracia) e sua qualificação para o trabalho (BRASIL, 1988, Art. 205).

\section{REFERÊNCIAS}

ALMEIDA, N. R. Boaventura Sousa Santos. A democracia nunca foi compatível com o capitalismo. Jornal I, 23 abr. 2018. Disponível em: https://ionline.sapo.pt/609373. Acesso em: 10 nov. 2018.

AMZOP. Estatuto da Associação dos Municípios da Zona da Produção. 2013.

BARDIN, L. Análise de conteúdo. Lisboa: Edições 70, LDA, 2011.

BRASIL. Constituição (1988). Constituição da República Federativa do Brasil. Brasília, DF: Senado, 1988.

BRASIL. Decreto n. 6.094, de 24 de abril de 2007. Plano de Metas Compromisso Todos pela Educação. Brasília, DF, 15 abr. 2007a. Disponível em: http://www.planalto.gov.br/ccivil 03/ ato2007-2010/2007/decreto/d6094.htm. Acesso em: 10 jul. 2020.

BRASIL. Lei n. 10.172, de 9 de janeiro de 2001. Aprova o Plano Nacional de Educação e dá outras providências. Brasília, DF, 10 jan. 2001. Disponível em:

http://www.planalto.gov.br/ccivil_03/leis/leis_2001/110172.htm. Acesso em: 10 jul. 2020. 
BRASIL. Ministério da Educação e Cultura. Lei n. 9394, de 20 de dezembro de 1996. Lei de Diretrizes e Bases da Educação Nacional. Dispõe sobre as Diretrizes e Bases da Educação Nacional. Brasília, 23 dez. 1996. Disponível em:

http://www.planalto.gov.br/ccivil_03/leis/19394.htm. Acesso em: 10 jul. 2020.

BRASIL. Ministério da Educação. Módulo FUNDEB. Brasília: MEC, FNDE, 2009.

BRASIL. Ministério da Educação. O Plano de Desenvolvimento da Educação: Razões, Princípios e Programas. Brasília: MEC, 2007b.

BRASIL. Ministério da Educação. Plano de Ações Articuladas: 2016-2019. Manual do usuário Etapa Planejamento. Brasília, DF: MEC, 2017.

BRASIL. Ministério da Educação. Plano de Ações Articuladas: 2016-2019. Manual do usuário Etapa Preparatória e Diagnóstico. Brasília, DF: MEC, 2016.

BRASIL. Ministério da Educação. Secretaria de Educação Básica. Lei n. 13.005, de 25 de junho de 2014. Brasília, DF, 26 jun. 2014. Disponível em:

http://www.planalto.gov.br/ccivil_03/_ato2011-2014/2014/lei/113005.htm. Acesso em: 10 jul. 2020.

CASTRO, A.; LAUANDE, M. A descentralização como componente da gestão educacional. In: ASSOCIAÇÃO NACIONAL DE POLÍTICA E ADMINISTRAÇÃO DA EDUCAÇÃO, 8., 2009, Vitória. Anais [...]. Vitória, ES: ANPAE, 2009. Disponível em:

http://www.anpae.org.br/congressos_antigos/simposio2009/08.pdf. Acesso em: 10 set. 2018.

FLICK, U. Introdução à metodologia de pesquisa: um guia para iniciantes. Trad. Magda Lopes. Porto Alegre: Penso, 2012.

FLICK, U. Introdução à pesquisa qualitativa. 3. ed. Porto Alegre: Artmed, 2009.

GIL, A. C. Como elaborar projetos de pesquisa. 4. ed. São Paulo: Atlas, 2002.

GIL, A. C. Métodos e técnicas de pesquisa social. 6. ed. São Paulo: Atlas, 2008.

LAKATOS E. M; MARCONI M. A. Fundamentos de metodologia científica. 5. ed. São Paulo. Atlas, 2003.

LÜCK, H. A. Concepções e processos democráticos de gestão educacional. 9. ed. Petrópolis, RJ: Editora Vozes, 2013. (Série Cadernos de Gestão)

MARTINS, P. S. O financiamento da educação básica como política pública. RBPAE, v. 26, n. 23, p. 497-514, set./dez. 2010. Disponível em:

https://seer.ufrgs.br/rbpae/article/download/19795/11533. Acesso em: 10 mar. 2018.

SANTOS, B. S. A difícil democracia: reinventar as esquerdas. São Paulo: Boitempo, 2016.

SAVIANI, D. O plano de desenvolvimento da educação: análise do projeto do MEC.

Educação e Sociedade, Campinas, v. 28, n. 100, p. 1231-1255, out. 2007. DOI:

http://dx.doi.org/10.1590/S0101-73302007000300027 
TRIVIÑOS, A. N. S. Introdução à pesquisa em ciências sociais: a pesquisa qualitativa em educação. São Paulo: Atlas, 1987.

YIN, R.K. Estudo de caso: planejamento e métodos. 2. ed. Porto Alegre: Bookman, 2001.

\section{Como referenciar este artigo}

CICHELERO, S. M. T.; LUNARDI, E. M.; ZINN, C. L. Plano de Ações Articuladas na gestão da educação de municípios pertencentes à as sociação dos municípios da zona da produção (AMZOP)-RS. Revista Ibero-Americana de Estudos em Educação, Araraquara, v. 16, n. esp. 2, p. 1093-1112, maio 2021. e-ISSN: 1982-5587. DOI: https://doi.org/10.21723/riaee.v16iesp2.15117

Submissão em: $15 / 12 / 2020$

Revisões requeridas em: 28/01/2021

Aprovado em: 03/03/2021

Publicado em: 01/05/2021 